\title{
Experts Review on Factors to Consider When Designing Virtual Environment for Stress Therapy
}

\author{
Farhah Amaliya Zaharuddin $^{1 *}$, Nazrita Ibrahim², Azmi Mohd Yusof ${ }^{3}$ \\ ${ }^{1}$ UNITEN R\&D Sdn Bhd, Universiti Tenaga Nasional, Kajang, Malaysia \\ ${ }^{2}$ Institute of Informatics, Computing and Energy, Universiti Tenaga Nasional, Kajang, Malaysia \\ ${ }^{3}$ College of Computing and Informatics, Universiti Tenaga Nasional, Kajang, Malaysia \\ farhahdin@gmail.com ${ }^{1}$
}

Article History: Received: 10 November 2020; Revised: 12 January 2021; Accepted: 27 January 2021; Published online: 05 April 2021

\begin{abstract}
Virtual reality (VR) based therapy is an alternative technique available for stress treatment. In this technique, virtual reality is used as a tool to assist users to reduce stress and induce relaxation. Many previous literatures published have acknowledged the effectiveness of virtual reality based therapy as compared to other techniques such as breathing exercise and imagination. However, previous studies available only focused on proving the effectiveness of virtual reality application in reducing stress, but are lacking discussions on factors that should be taken into consideration when designing its virtual environment. In previous study, initial framework containing possible factors to be considered when designing virtual environment for stress therapy has been proposed. In this paper, an expert review was conducted to validate the usefulness of the identified factors. Findings from the validation process has resulted in the improved version of the initial framework and their application in virtual environment.
\end{abstract}

Keywords: virtual environment, virtual reality, stress therapy, design factors

\section{Introduction}

Virtual reality (VR) is a computer-generated simulation of 3D environment with the ability to trick user's mind into believing that the displayed environment is real with the help of special sensors and display. Virtual reality has been used in various areas such as tourism (Guttentag, 2010), medical training (Ruthenbeck \& Reynolds, 2015) and engineering design (Fernández \& Alonso, 2015). As technology evolves, the application of virtual reality has been extended into psychological field. In psychology, virtual reality has been used as a therapy tool for mental health problems such as post-traumatic stress disorder (Menelas, Haidon, Ecrepont, \& Girard, 2018), phobia (Suyanto, Angkasa, Turaga, \& Sutoyo, 2017) and anxiety (Anderson et al., 2013). Most of the studies conducted to identify the effectiveness of virtual reality as an alternative for mental health therapy resulted in promising results. This has encouraged researchers to further enhance the virtual reality application as an alternative treatment of another psychological problem which is stress.

Stress, which is the main factor of depression is a common health issue that is arising all around the world. Currently, there are several techniques available for stress therapy which are breathing exercise, meditation and imagination. However, these conventional techniques have several disadvantages. Among the disadvantages are long time taken for a person to be in the state of tranquility and high energy required to stay focused throughout the therapy session. Therefore, to overcome the disadvantages identified, virtual reality based therapy has been proposed to be used as an alternative for stress therapy. Virtual reality based therapy is a technique which utilizes virtual reality technology as a stress reduction and relaxation tool. By using this technique, relaxing environment such as beach is displayed to user through special devices, for instance, head mounted display (HMD). Hence, less energy and time are required for the user to be in relaxation state.

Many articles published have acknowledged the effectiveness of virtual reality as a stress therapy tool as compared to other conventional techniques (Mahalil, Rusli, Yusof, Yusof, \& Zainudin, 2014; Hussain et al. 2017; Taneja, Vishal, Mahesh, \& Geethanjali, 2017). However, majority of the studies conducted only focused on proving its effectiveness as compared to the conventional methods. Little discussion on factors that should be taken into consideration when designing its virtual environment are available for reference. This situation leaves future researchers with the problem of a very few virtual environment design guidelines specifically for stress therapy available to be referred.

It is assumed that virtual environment plays a big role in assisting the user to feel relax. Therefore, proper design should be implemented into the virtual environment to ensure the system is useful. According to Garrett et al. (2018), clinical virtual reality research which includes virtual reality in psychological area is generally at the early stage where there are various technical and theoretical issues that need to be looked into. One of the issues highlighted was the use of non-standardize techniques and tools in the studies. The issue highlighted by 
Garret et al. supports the gap of unavailability of guideline to be referred to when designing a virtual environment specifically for stress therapy.

\section{Initial Framework Background}

The initial factors of the framework were derived from two studies which were literature review (Zaharuddin, Ibrahim, Rusli, Mahidin, \& Yusof, 2019) and existing system review (Zaharuddin, Ibrahim, Yusof, Rusli, \& Mahidin, 2019). Data triangulation method was used to combine all the studies' finding. The triangulation process resulted in identification of six possible factors and their own elements. Besides, the two studies conducted also resulted in obtaining recommendations on how to apply the factors in the virtual environment. Table 1 shows the initial framework proposed which consists of six factors, their elements and its application in a virtual environment.

Table 1. Initial factors to consider when designing virtual environment for stress therapy

\begin{tabular}{|c|c|c|}
\hline Factors & Elements & Application in virtual environment \\
\hline \multirow{3}{*}{$\begin{array}{l}\text { Visual } \\
\text { attraction }\end{array}$} & Water feature & Presence of water feature such as river, waterfall and water fountain. \\
\hline & Social support & $\begin{array}{l}\text { Presence of people in the surrounding area such as people jogging } \\
\text { around. }\end{array}$ \\
\hline & Animals element & Presence of animal feature such as fish, duck and bird. \\
\hline \multirow{3}{*}{$\begin{array}{l}\text { Environment } \\
\text { setting }\end{array}$} & Nature based theme & As the main theme for visual and audio aspects. \\
\hline & Additional audio & Include religious and instrumental based music. \\
\hline & Lighting & Use daylight instead of nightlight. \\
\hline \multirow{3}{*}{ Navigation } & Free teleportation & User can teleport anywhere without boundaries. \\
\hline & $\begin{array}{l}\text { Semi-guided } \\
\text { teleportation }\end{array}$ & $\begin{array}{l}\text { User can teleport at certain viewpoints, pre-set during the } \\
\text { developmental phase. }\end{array}$ \\
\hline & Guided teleportation & $\begin{array}{l}\text { Exploration path is pre-set during the developmental phase. User do not } \\
\text { have the ability to control which viewpoints to be at. }\end{array}$ \\
\hline \multirow{2}{*}{ Interaction } & Passive interaction & User sit back, relax, and enjoy the view. \\
\hline & Active interaction & Active user involvement with the virtual environment such as fishing. \\
\hline $\begin{array}{l}\text { User } \\
\text { comfort }\end{array}$ & Safety & $\begin{array}{l}\text { Safety elements should be considered before any objects or situations } \\
\text { are included. }\end{array}$ \\
\hline \multirow[b]{2}{*}{ Realism } & Visual realism & Presence of shadow, movement and logical placement. \\
\hline & Auditory realism & $\begin{array}{l}\text { Right usage of audio according to visual. For example, closer distance } \\
\text { to a water fountain should be accompanied with an increased water } \\
\text { sound volume. }\end{array}$ \\
\hline
\end{tabular}

\section{Validation of Proposed Factors}

A prototype implementing all six factors were developed to be used as an evaluation tool. An expert's review study was conducted to evaluate the proposed factors and its concepts of implementation. The aim of the evaluation was to validate the usefulness of the factors in reducing stress. The evaluation was not meant to validate the factors in term of their correctness but, to evaluate in terms of their usefulness. It is inferred that the correctness of the proposed factors to help in reducing ones' stress level is difficult to measure as individual preferences may vary, making the overall findings rather subjective. Due to this reason, for this study, factors favored by majority of the participants is an indicator of factors that may benefit majority of the society as well.

\subsection{Evaluation method}

This study used expert review technique to validate the proposed factors and their application in the virtual environment similar to Hussain et al. (2016). Experts' selection were randomly made based on two criteria: i) should have $\mathrm{PhD}$ qualification and ii) the fields of expertise and interest should be in human psychology or information technology or visual design related area. Six experts; one counsellor, one clinical psychologist, and four academicians participated in the review.

The review was conducted in four stages. The first stage was, where the research background was explained and presented to the experts. The aim of this stage was to give the experts some brief ideas on the objectives and purpose of the study. While the second stage includes an explanation of the proposed factors. In this stage, the expert was explained on how the factors were derived from two background studies. Additionally, explanation on how the factors can actually be implemented in the prototype was also included. The third stage was, prototype demonstration. In demonstrating the prototype, the experts were invited to experience the proposed factors in the 
environments made using virtual reality devices. Experts who declined the offer to experience the prototype were presented with a demonstration of the system by the researchers themselves. The last stage was the interview session. The experts were interviewed on their individual opinions of the factors and prototype demonstrated. All interview sessions were audio recorded and transcribed for analysis purpose.

\subsection{Data preparation for analysis}

The recorded interviews were transcribed word by word. Short verbal expressions such as "haah" and "ermm" were also included in the transcriptions since such expression may convey the experts' thought, feeling or impression. Upon the completion of the transcription process, the transcribed scripts were revised as the researcher replayed and listened to the recorded audio. This was done to ensure that the audio was correctly transcribed. Once completed, the scripts were once again reviewed for the second time. The second review only required the researcher to read the script without listening to the recorded audio. The aim of the second review was to help the researcher to become more familiar with the content of the scripts and understand the overall view of the expert's feedback.

\subsection{Data analysis}

Data analysis for this study were divided into two stages which were the identification of factor usefulness and the identification of suggestions on improvisation.

Stage 1: Identification of factor usefulness. All scripts were analyzed by using content analysis method in order to identify the experts' feedback as well as to determine the feedback frequency. The feedback were categorized into two; agreement and disagreement. A statement is considered as an agreement when it expresses the experts' acceptance towards the proposed factors and their application in virtual environment. Any statement containing suggestions on improvisation is also considered as an agreement even though the statement did not contain any direct approval words such as "yes" and "I agree". This is because, when an improvement is suggested, it was not due to the fallacy of the factor, but was rather because it was based on the experts' knowledge and experience, which foresees some possible refinements. Meanwhile, a statement is considered as a disagreement when it expresses the experts' disapproval or difference in opinion of the proposed factors. Both agreement and disagreement frequencies for each factor was recorded to identify its usefulness in reducing stress.

Stage 2: Identification of suggestions on improvisation. At this stage, all agreeing statements listed in the previous stage (Stage 1) were reviewed one by one to identify any possible improvement suggestions. Suggestion of improvisations were divided into two which were improvisations on the factors as well as improvisations of the application of the factors in virtual environment itself. Improvement suggestion for factors may include rewording, restructuring, combining, separating, renaming and revising the factors. Whereas, improvement suggestion for application may include adjusting colour contrast and smoothing objects' animation in the prototype.

\section{Result and Discussion}

Result presented in this article are divided into two parts; Part 1: Usefulness of proposed factors and Part 2: Updated factors and their application in virtual environment as result of improvement suggested by the experts.

\subsection{Part 1: Result for usefulness of proposed factors}

This result helps researcher to validate the usefulness of the proposed factors in assisting a person to reduce stress. Feedback received from the experts were recorded as shown in Table 2. Due to the difference in the area of expertise that the experts hold, a majority of them therefore preferred to comment on the factors only based on their knowledge of expertise. Hence, explains the 'no comment' indicator in Table 2.

Table 2. Experts' feedback on initial factors to be considered when designing a stress therapy virtual reality

\begin{tabular}{|c|c|c|c|c|c|c|c|}
\hline Factor & Element & $\begin{array}{l}\text { Expert } \\
1 \\
\text { (E1) }\end{array}$ & $\begin{array}{l}\text { Expert } \\
2 \\
\text { (E2) }\end{array}$ & $\begin{array}{l}\text { Expert } \\
3 \\
\text { (E3) }\end{array}$ & $\begin{array}{l}\text { Expert } \\
4 \\
(\mathbf{E} 4)\end{array}$ & $\begin{array}{l}\text { Expert } \\
5 \\
(\mathrm{E5})\end{array}$ & $\begin{array}{l}\text { Expert } \\
6 \\
\text { (E6) }\end{array}$ \\
\hline \multirow{3}{*}{ Visual attraction } & Water feature & $\sqrt{ }$ & - & $\sqrt{ }$ & $\sqrt{*}$ & $\sqrt{*}$ & $\sqrt{ }$ \\
\hline & Social support & $\sqrt{ }$ & - & $\sqrt{ }$ & $\sqrt{*}$ & $\sqrt{*}$ & $\sqrt{*}$ \\
\hline & Animals element & $\sqrt{ }$ & $\sqrt{ }$ & $\sqrt{ }$ & $\sqrt{ } *$ & $\sqrt{*}$ & $\sqrt{ }$ \\
\hline \multirow{3}{*}{$\begin{array}{l}\text { Environment } \\
\text { setting }\end{array}$} & Nature based theme & $\sqrt{ }$ & $\sqrt{ }$ & - & $\sqrt{ }$ & $\sqrt{ }$ & $\sqrt{ }$ \\
\hline & Additional audio & $\sqrt{ }$ & $\sqrt{ }$ & - & $\sqrt{ }$ & $\sqrt{ }$ & $\sqrt{ }$ \\
\hline & Lighting & $\sqrt{ }$ & $\sqrt{ }$ & - & $\sqrt{ }$ & $\sqrt{ }$ & $\sqrt{ }$ \\
\hline
\end{tabular}




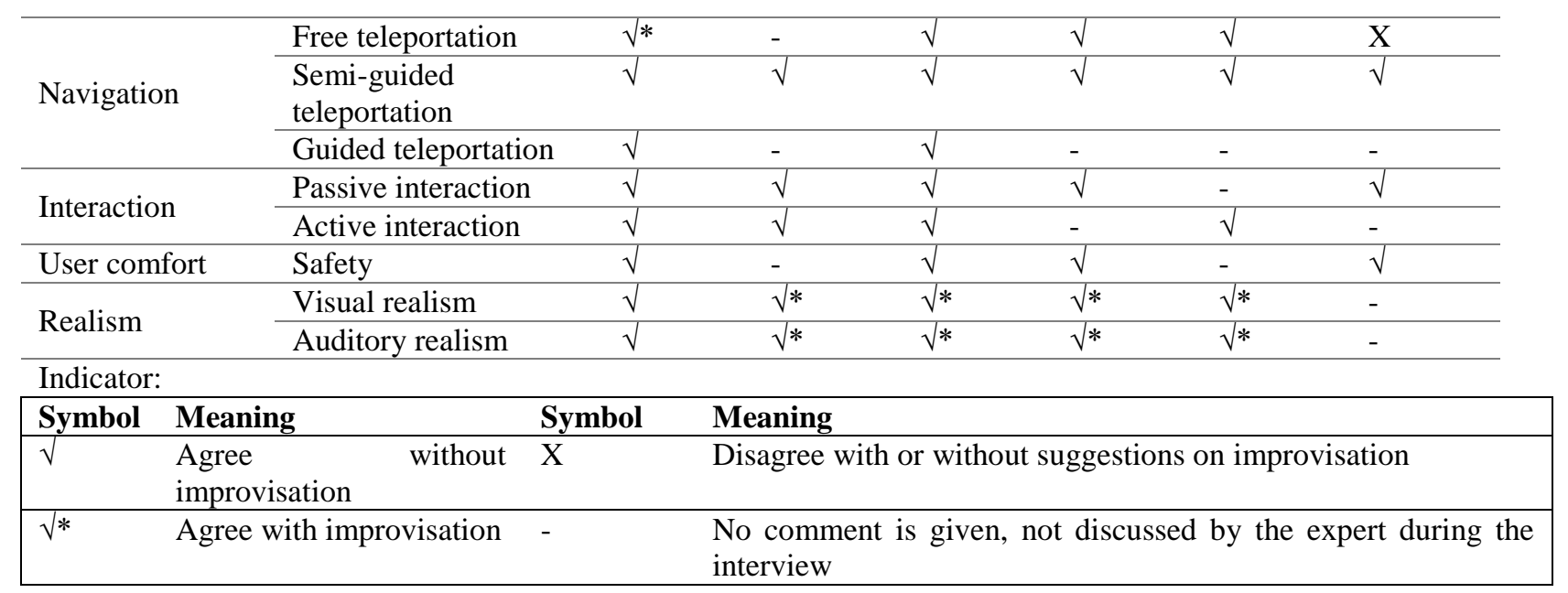

Referring to the Table 2, majority of the experts agreed with the proposed factors presented to them. However, most of the agreement came with suggestions of improvisations that should be looked into. Threshold level of satisfaction for this study was set into three agreements, based on the average number of experts who participated in this study. Based on the tabulated result, all of the factors except for guided teleportation received more than three agreements, with and without suggestions for improvisation. This result shows that all of the proposed factors except for guided teleportation are considered to be useful in assisting users to reduce their stress. Even though guided teleportation did not receive a satisfied number of agreement, it does not mean that the element has totally no impact in assisting users to feel relax, but this rather indicates that the application of guided navigation in the virtual environment may cater stress reduction assistance to only a small number of users.

\subsection{Part 2: Updated factors and their application in virtual environment}

Both proposed factors and their application in virtual environment were revised based on the experts' feedback as identified in Table 2. Table 3 shows the updated version of factors and their application in virtual environment. Changes made from the initial framework (Table 1) are highlighted in Italic.

The first improvisation made was done by merging two visual attraction elements into one single element. The initial proposed elements were then suggested to be the recommendation of new element in the application. This improvisation was made after considering the feedback received from two experts. According to them, water feature and animal elements were more likely be the example of elements that stimulate users' attention rather than the elements that should be included in the environment. It is not suitable to limit the attention attracting elements to only two. There is a variety of potential elements to be included in order to catch users' attention which may not be related to water and animal. Therefore, the experts recommended not to set any restriction on the visual attraction element, thus improving the factor by suggesting a new generic element.

Table 3. Updated factors and their application in virtual environment

\begin{tabular}{|c|c|c|}
\hline Factor & Element & Application in Virtual Environment \\
\hline $\begin{array}{l}\text { Visual } \\
\text { attraction }\end{array}$ & $\begin{array}{l}\text { Fascination } \\
\text { stimuli }\end{array}$ & $\begin{array}{l}\text { This element should be applied through two features which are presence of } \\
\text { water and presence of animals. }\end{array}$ \\
\hline \multirow{4}{*}{$\begin{array}{l}\text { Environment } \\
\text { setting }\end{array}$} & $\begin{array}{l}\text { Nature based } \\
\text { theme }\end{array}$ & $\begin{array}{l}\text { Use nature based theme as the main theme for visual and audio aspects. For } \\
\text { visual, nature environment such as beach can be implemented. In terms of audio, } \\
\text { nature based audio that suit the environment should be used. }\end{array}$ \\
\hline & Lighting & Use daylight theme as the main lighting theme. \\
\hline & $\begin{array}{l}\text { Additional } \\
\text { audio }\end{array}$ & Include religion based audio and instrumental based audio as additional audio. \\
\hline & Realism & $\begin{array}{l}\text { Apply to both visual and audio aspects. Visual realism can be achieved by } \\
\text { including shadows, right movement and logical placement. Audio realism can be } \\
\text { implemented through its loudness where the loudness should be according to } \\
\text { visual distance. }\end{array}$ \\
\hline $\begin{array}{l}\text { Environment } \\
\text { exploration }\end{array}$ & $\begin{array}{l}\text { Free } \\
\text { exploration }\end{array}$ & $\begin{array}{l}\text { Users are allowed to freely explore the environment except for unnecessary } \\
\text { place such as on top of a tree. Boundaries are set to prevent the users from } \\
\text { going to the unnecessary place. }\end{array}$ \\
\hline
\end{tabular}




\begin{tabular}{|c|c|c|}
\hline & $\begin{array}{l}\text { Pre-defined } \\
\text { viewpoint }\end{array}$ & $\begin{array}{l}\text { Users are allowed to explore the environment between pre-set viewpoints. The } \\
\text { viewpoints are set by the developers after considering the suitability of the } \\
\text { places as relaxation viewpoints. }\end{array}$ \\
\hline & $\begin{array}{l}\text { Pre-defined } \\
\text { path }\end{array}$ & Users are cruised around the environment. \\
\hline \multirow{2}{*}{ Interaction } & $\begin{array}{l}\text { Passive } \\
\text { interaction }\end{array}$ & $\begin{array}{l}\text { No activity is recommended to be included for this type of interaction. Users will } \\
\text { just sit back and enjoy the view without doing anything. }\end{array}$ \\
\hline & $\begin{array}{l}\text { Active } \\
\text { interaction }\end{array}$ & $\begin{array}{l}\text { Interactive therapeutic activities are set for users to interact with the } \\
\text { environment. Users are expected to give commands to the environment with the } \\
\text { aim of completing the task. }\end{array}$ \\
\hline \multirow{2}{*}{$\begin{array}{l}\text { User } \\
\text { comfort }\end{array}$} & Safety & $\begin{array}{l}\text { Safety elements should be considered before any objects or situations are } \\
\text { included. }\end{array}$ \\
\hline & $\begin{array}{l}\text { Social } \\
\text { support }\end{array}$ & $\begin{array}{l}\text { Presence of virtual people mingle around in the environment such as cyclist } \\
\text { cycling around a park or men jogging around. }\end{array}$ \\
\hline
\end{tabular}

The second improvisation made was restructuring of realism factor. In the initial framework, realism was proposed to be the sixth factor. However, four of the experts suggested to include the factor as one of the environment setting elements. This was done due to the fact that the elements listed under realism factor focused only on visual and audio aspects. As environment setting factor was the only factor proposed that are related to visual and audio aspects of the virtual environment, therefore, it is more appropriate if realism is listed as one of its elements. In the updated version, realism is part of environment setting factor, which is recommended to be implemented into the virtual environment through two aspects which were visual and audio realism.

The third improvisation made was rewording the name of factor and elements proposed for navigation. Initially, navigation was proposed to describe the way in which the users should explore the virtual environment. However, based on the experts' comment, the words used to portray this factor and its elements were not accurate. According to the expert, navigation requires interaction. This therefore means that, it could be a part of interaction factor since users need to interact with the system in order to navigate themselves around the environment. Due to this reason, after considering the comments received from the experts, the word navigation was changed to environment exploration to represent wayfinding. The same comment was also given for elements proposed under navigation factor. The word teleportation used does not represent the true meaning of the elements. From the researcher's point of view, teleportation refers to a mode through which the users will explore the environment. However, based on the experts' opinion, teleportation is a navigational technique in virtual reality, not the method of environment exploration. Taking the feedback into consideration, terms used for the three elements proposed were reworded to free exploration, pre-defined viewpoint and pre-defined path. The fourth improvisation made was restructuring of social support element. In the initial framework, social support was proposed to be listed under visual attraction factor. However, based on researcher's explanation on the purpose of this element which is to prevent the users from feeling lonely and isolated, three experts suggested to relocate the element to become one of user comfort elements. This was done due to the purpose of the element which was to provide comfort to the users, rather than attracting the users' attention.

\section{Conclusion}

This paper presented the finding of experts' review on the proposed factors to be considered when designing a virtual environment for stress therapy. Six experts from different domains reviewed and commented on the proposed factors and their application in virtual environment. Overall, the majority of the experts agreed with the proposed framework. However, there were several improvisations suggested by the experts in order to enhance the usefulness of the factors. Both feedbacks and suggestions received were used to refine the initial factors and improvise the prototype developed. Future works of this study could be an evaluation of the proposed factors and their application with potential end users.

\section{Acknowledgment}

This study was funded by Tenaga Nasional BIC Grant (U-TE-PC-19-03). We would like to thank UNITEN R\&D Sdn. Bhd. for fund management.

\section{References}

1. Anderson, P. L., Price, M., Edwards, S. M., Obasaju, M. A., Schmertz, S. K., Zimand, E., \& Calamaras, M. R. (2013). Virtual reality exposure therapy for social anxiety disorder: A 
randomized controlled trial. Journal of Consulting and Clinical Psychology, 81(5), 751-760. https://doi.org/10.1037/a0033559

2. Fernández, R. P., \& Alonso, V. (2015). Virtual Reality in a shipbuilding environment. Advances in Engineering Software, 81, 30-40.

3. Garrett, B., Taverner, T., Gromala, D., Tao, G., Cordingley, E., \& Sun, C. (2018). Virtual Reality Clinical Research: Promises and Challenges. JMIR Serious Games, 6(4), e10839. https://doi.org/10.2196/10839

4. Guttentag, D. A. (2010). Virtual reality: Applications and implications for tourism. Tourism Management, 31(5), 637-651. https://doi.org/https://doi.org/10.1016/j.tourman.2009.07.003

5. Hussain, A., Mkpojiogu, E.O.C., Almazini, H., Almazini, H. (2017). Assessing the usability of Shazam mobile app. AIP Conference Proceedings, 1891, art. no. 020057.

6. Hussain, A., Mkpojiogu, E.O.C. (2016). Requirements: Towards an understanding on why software projects fail. AIP Conference Proceedings, 1761, art. no. 020046.

7. Mahalil, I., Rusli, M. E., Yusof, A. M., Yusof, M. Z. M., \& Zainudin, A. R. R. (2014). Virtual reality-based technique for stress therapy. In 2014 4th International Conference on Engineering Technology and Technopreneuship (ICE2T) (pp. 295-300). Kajang: IEEE. https://doi.org/10.1109/ICE2T.2014.7006265

8. Menelas, B.-A. J., Haidon, C., Ecrepont, A., \& Girard, B. (2018). Use of virtual reality technologies as an Action-Cue Exposure Therapy for truck drivers suffering from Post-Traumatic Stress Disorder. Entertainment Computing, 24(Supplement C), 1-9. https://doi.org/https://doi.org/10.1016/j.entcom.2017.10.001

9. Ruthenbeck, G. S., \& Reynolds, K. J. (2015). Virtual reality for medical training: The state-of-theart. Journal of Simulation, 9(1), 16-26. https://doi.org/10.1057/jos.2014.14

10. Suyanto, E. M., Angkasa, D., Turaga, H., \& Sutoyo, R. (2017). Overcome Acrophobia with the Help of Virtual Reality and Kinect Technology. Procedia Computer Science, 116(Supplement C), 476-483. https://doi.org/https://doi.org/10.1016/j.procs.2017.10.062

11. Taneja, A., Vishal, S. B., Mahesh, V., \& Geethanjali, B. (2017). Virtual reality based neurorehabilitation for mental stress reduction. In 2017 Fourth International Conference on Signal Processing, Communication and Networking (ICSCN) (pp. 1-5). IEEE. https://doi.org/10.1109/ICSCN.2017.8085665

12. Zaharuddin, F. A., Ibrahim, N., Rusli, M. E., Mahidin, E. M. M., \& Yusof, A. M. (2019). Factors to Consider When Designing a Virtual Environment to Treat Stress. In International Visual Informatics Conference (pp. 36-47). Springer.

13. Zaharuddin, F. A., Ibrahim, N., Yusof, A. M., Rusli, M. E., \& Mahidin, E. M. M. (2019). Virtual Environment for VR-Based Stress Therapy System Design Element: User Perspective. In International Visual Informatics Conference (pp. 25-35). Springer. 